\title{
"Analysis Influence Brand Equity and Service Quality to Costumer Satisfaction Users Blackberry Curve 9300 District Sario Manado"
}

\author{
By; \\ FERDY RORING \\ ferdy_rr77@yahoo.com
}

\begin{abstract}
Research In Motion (RIM) is the official producer of mobile phones that are currently most popular especially in Indonesia which is the Blackberry. Indonesia is a large market share to Blackberry because of Indonesia's population. 47 percent mobile circulating in Indonesia is Blackberry. The goal of this research is to know the influence of quality of service and brand equity to the satisfaction of consumer users blackberry curve 9300 district Sario the city of manado.

In this research, the methods of analysis used is regression analysis method. The population was taken is the blackberry curve 9300 user with samples as much as 100 people. Sampling techniques research using simple random sampling.

Research results by using regression analysis showed that partially variable quality of service significantly influential to the variable satisfaction but rather to brand equity, does not affect the consumer's satisfaction. And simultaneously variable quality of service and significant impact on brand equity consumer satisfaction

For the RIM Blackberry mobile phone manufacturers should be as much again to improve the quality of service that is better to consumers so that consumers do not migrate or switch to other parties. More manufacturers to optimize quality of service to the higher customer satisfaction. The RIM also should pay attention to brand equity. If the RIM is not paying attention to the brand equity will be decreased to the level of consumer satisfaction that have an impact on decreasing the level of product sales.
\end{abstract}

Keywords: service quality, brand equity, and customer satisfaction

\section{PENDAHULUAN}

\author{
Dalam bidang telekomunikasi, \\ perkembangan teknologi berkembang \\ sangat pesat. Hampir setiap tahun selalu \\ bermunculan teknologi - teknologi baru
}

yang canggih. Telekomunikasi saat ini

menjadi bidang yang sangat penting. Tanpa

adanya komunikasi, suatu hubungan tidak

akan terjalin. Baik itu hubungan bisnis

maupun hubungan lainnya. Salah satu

teknologi dalam bidang telekomunikasi yang

berkembang pesat adalah handphone.

Handphone merupakan alat untuk menjalin

komunikasi antara satu orang dengan orang lainnya walaupun orang tersebut berbeda

tempat. Handphone saat ini telah menjadi

salah satu kebutuhan manusia. Tanpa

handphone, kita akan merasa kekurangan

informasi atau bahkan ketinggalan jaman.

Karena melalui handphone saat ini

masyarakat dapat menjalin hubungan yang

lebih luas dengan semua orang baik dalam

hal bisnis maupun hal - hal lainnya yang

memberikan manfaat yang baik bagi

mereka.

Perkembangan smartphone yang

begitu gencar, telah membuatnya

melampaui jumlah pengiriman Personal

Computer (PC), seperti desktop laptop 
maupun tablet. Seperti penelitian yang telah dilakukan oleh biro riset Canalys tahun 2011 lalu, vendor smartphone telah mengirimkan 488 juta unit yang melampaui jumlah perangkat PC sebesar 415 juta. Pengiriman smartphone ini tumbuh sebesar 62,7 persen dibandingkan tahun 2010.

Tabel. Data Penjualan Smartphone

\section{Tahun 2011}

\begin{tabular}{|c|c|}
\hline Jenis Smartphone & Jumlah Unit (juta) \\
\hline Apple & 93,1 \\
\hline Samsung & 91,9 \\
\hline Blacberry OS & 51,4 \\
\hline Symbian & 80,1 \\
\hline $\begin{array}{c}\text { Windows Phone } \\
\text { (Microsoft) }\end{array}$ & 6,8 \\
\hline Lain - Lain & 5,4 \\
\hline Total & $\mathbf{3 2 8 , 7}$ \\
\hline
\end{tabular}

Sumber : Biro Riset Canalys tahun 2011

Tipe Blackberry Gemini 8520 dan Blackberry Curve 9300 adalah yang paling banyak dicari oleh masyarakat di Indonesia. Kedua tipe ini merupakan tipe yang paling laris dipasaran. Mengapa demikian ? hal ini dikarenakan harga dari kedua tipe ini yang bertaraf kelas menengah kebawah. Dimana mayoritas dari penduduk Indonesia tergolong menengah kebawah. Harga untuk Blackberry Gemini 8520 berkisar Rp 1.600.000, sedangkan Blackberry Curve 9300 berkisar Rp. 2.150.000. Harga yang ditentukan oleh pihak RIM ini dapat terjangkau oleh masyarakat kelas menengah kebawah. Jadi pihak RIM berhasil menarik minat beli masyarakat untuk membeli produk Blackberry tersebut.
Berdasarkan fenomena - fenomena yang ada dan uraian di atas, maka peneliti mengambil judul penelitian yaitu Pengaruh Kualitas Pelayanan Dan Ekuitas Merek Terhadap Kepuasan Konsumen Pengguna Blackberry Curve 9300 Di Kecamatan Sario Kota Manado.

\section{Perumusan masalah}

Berdasarkan uraian yang dipaparkan pada latar belakang di atas, maka rumusan masalah pada penelitian ini adalah sebagai berikut.

1. Apakah kualitas pelayanan berpengaruh terhadap kepuasan konsumen pengguna Blackberry Curve 9300 di Kecamatan Sario, kota Manado ?

2. Apakah ekuitas merek berpengaruh terhadap kepuasan konsumen pengguna Blackberry Curve 9300 di Kecamatan Sario, kota Manado ?

3. Apakah kualitas pelayanan dan ekuitas merek secara bersama sama berpengaruh terhadap kepuasan konsumen pengguna Blackberry Curve 9300 di Kecamatan Sario kota Manado

\section{Tujuan Penelitian}

Berdasarkan rumusan masalah diatas, maka tujuan penelitian ini adalah 
1. Menganalisis pengaruh kualitas pelayanan terhadap kepuasan konsumen pengguna Blackberry Curve 9300 di Kecamatan Sario, kota Manado

2. Menganalisis pengaruh ekuitas merek terhadap kepuasan konsumen pengguna Blackberry Curve 9300 di Kecamatan Sario Kota Manado

3. Menganalisis pengaruh secara bersama - sama antara kualitas pelayanan dan ekuitas merek terhadap kepuasan konsumen pengguna Blackberry Curve 9300 di Kecamatan Sario Kota Manado

\section{Manfaat penelitian}

1. Manfaat Akademis

Menerapkan ilmu yang telah diperoleh dalam penelitiian ini serta mempertajam pengetahuan serta wawasan

\section{Manfaat Praktis}

Bagi perusahaan blackberry, memberikan manfaat secara teoritis bagi pengembangan pangsa pasar dan omset penjualan blackberry di Kecamatan Sario kota Manado dan juga untuk mempertahankan para pelanggan blackberry.

\section{TINJAUAN PUSTAKA}

\section{Pengertian Kualitas Pelayanan}

Kualitas pelayanan dapat diartikan sebagai upaya pemenuhan kebutuhan dan keinginan konsumen serta ketepatan penyampaiannya dalam mengimbangi harapan konsumen (Tjiptono, 2007). Kualitas pelayanan (service quality) dapat diketahui dengan cara membandingkan persepsi para konsumen atas pelayanan yang nyata-nyata mereka terima / peroleh dengan pelayanan yang sesungguhnya mereka harapkan / inginkan terhadap atribut-atribut pelayanan suatu perusahaan.

Menurut Kotler (2002:83) definisi pelayanan adalah setiap tindakan atau kegiatan yang dapat ditawarkan oleh suatu pihak kepada pihak lain, yang pada dasarnya tidak berwujud dan tidak mengakibatkan kepemilikan apapun. Produksinya dapat dikaitkan atau tidak dikaitkan pada satu produk fisik. Pelayanan merupakan perilaku produsen dalam rangka memenuhi kebutuhan dan keinginan konsumen demi tercapainya kepuasan pada konsumen itu sendiri. Kotler juga mengatakan bahwa perilaku tersebut dapat terjadi pada saat, sebelum dan sesudah terjadinya transaksi. 


\section{Pengertian Ekuitas Merek}

Menurut Kotler dan Amstrong (2007;349-350) merek adalah suatu nama, kata, tanda, simbol, atau desain, atau kombinasi dari semuanya yang mengidentifikasikan pembuat atau penjual produk atau jasa tertentu. Sedangkan ekuitas merek adalah nilai suatu merek berdasarkan seberapa kuat merek tersebut mempunyai loyalitas merek, kesadaran konsumen akan nama merek, kualitas yang dipersepsikan, asosiasi merek, dan berbagai aset lainnya seperti paten, merek dagang, dan hubungan jaringan distribusi.

\section{Pengertian Kepuasan Konsumen}

Secara umum, kepuasan adalah perasaan senang atau kecewa seseorang yang muncul setelah membandingkan kinerja (hasil) produk yang dipikirkan terhadap kinerja (atau hasil) yang diharapkan. Menurut Kotler (2001 : 46) menandaskan bahwa kepuasan konsumen adalah tingkat perasaan seseorang setelah membandingkan kinerja (atau hasil) yang ia rasakan dibandingkan dengan harapannya. Bila kinerja melebihi harapan mereka akan merasa puas dan sebaliknya bila kinerja tidak sesuai harapan maka akan kecewa.

\section{METODE PENELITIAN}

\section{Jenis Penelitian}

Metode penelitian yang digunakan dalam penelitian ini adalah metode penelitian kuantitatif. Metode penelitian Kuantitatif adalah metode penelitian yang berlandaskan pada filsafat positivisme, digunakan untuk meneliti pada populasi atau sampel tertentu, teknik pemgambilan sampel pada umumnya dilakukan secara random, pengumpulan data menggunakan instrumen penelitian, analisis data bersifat kuantitatif / statistik dengan tujuan untuk memguji hipotesis yang telah ditetapkan (Sugiyono, 2012;13).

Penelitian berdasarkan tingkat ekplanasinya terdiri dari 3 jenis yaitu penelitian deskriptif yaitu penelitian yang dilakukan untuk mengetahui nilai variable mandiri, baik satu variable atau lebih (independent) tanpa membuat perbandingan atau menghubungkan antara variable satu dengan yang lain. Kemudian penelitian komparatif yaitu suatu penelitian yang bersifat membandingkan. Serta yang terakhir adalah penelitian asosiatif, yaitu penelitian yang bertujuan untuk mengetahui hubungan antara dua variable atau lebih. Berdasarkan tingkat explanasinya, penelitian ini 
termasuk pada jenis penelitian asosiatif.

\section{Populasi dan Sampel}

\section{Populasi}

Dalam penelitian ini, populasi yang dimaksud adalah individu pengguna smartphone Blackberry Curve 9300 di kecamatan Sario. Dimana jumlah penduduk di kecamatan Sario menurut pendataan terakhir tahun 2010 yang dilakukan oleh pemerintah kecamatan Sario adalah 45.902 orang.

Sampel

Pada penelitian ini dengan
menggunakan cara dari Roscoe yaitu
menggunakan jumlah sampel minimal
dengan teknik sampel besar ( $\mathrm{N}=30)$.
Menurut statistik $\mathrm{N}=30 \quad$ (jumlah
responden/observasi) sebanyak 30 sudah
cukup memberikan hasil penelitian yang
baik karena $\mathrm{N}=30$ bisa menghasilkan
distribusi normal. Pada penelitian ini
menggunakan sampel sebanyak 100
responden. Angka 100 ini sudah diatas
batas minimal.

Jika tingkat kesalahan yang diinginkan (e) adalah10\%, N = 54959, maka jumlah sampel yang akan diteliti sebanyak :

$n=\frac{49906}{1+49906 \cdot(0.1)^{2}}=99,80$ dibulatkan menjadi 100
Kriteria yang ditetapkan oleh peneliti dalam menentukan sampel adalah hanya pengguna blackberry curve 9300 di kecamatan Sario.

\section{Metode Pengumpulan Data}

Data penelitian dapat dikelompokkan dalam dua jenis yaitu data primer dan data sekunder.

1. Data primer adalah data yang diperoleh atau dikumpulkan oleh peneliti secara langsung dari sumber datanya. Data primer disebut juga sebagai data asli atau data baru yang memiliki sifat up to date. Untuk mendapatkan data primer, peneliti harus mengumpulkannya secara langsung. Teknik yang dapat digunakan peneliti untuk mengumpulkan data primer antara lain observasi, wawancara, diskusi terfokus (focus grup discussion - FGD) dan penyebaran kuesioner.

2. Data Sekunder adalah data yang diperoleh atau dikumpulkan peneliti dari berbagai sumber yang telah ada (peneliti sebagai tangan kedua). Data sekunder dapat diperoleh dari berbagai sumber seperti Biro Pusat 
Statistik (BPS), buku, laporan, jurnal, dan lain-lain.

Teknik pengumpulan data yang dipilih untuk setiap variabel tergantung pada berbagai faktor terutama jenis data dan ciri responden. Teknik pengumpulan data pada penelitian ini adalah :

1. Kuesioner

Kuesioner adalah sejumlah pertanyaan tertulis yang digunakan untuk memperoleh informasi dari responden dalam arti laporan tentang pribadinya, atau hal-hal yang diketahui".

Kuesioner merupakan teknik pengumpulan data yang efisien bila peneliti tahu dengan pasti variabel yang akan diukur dan tahu apa yang bisa diharapkan dari respponden. Kuesioner juga cocok digunakan bila jumlah responden cukup besar dan tersebar di wilayah yang luas.

\section{Wawancara}

Wawancara informatif adalah suatu alat untuk memperoleh fakta/data informasi dari indivudu secara lisan. Dengan tujuan mendapatkan data yang diperlukan untuk bimbingan ( WS. Winkel, 1995 ).

\section{Studi Pustaka}

Studi pustaka dilakukan dengan cara mempelajari, mendalami, dan mengutip teori-teori atau konsep-konsep dari sejumlah literatur, baik buku, jurnal, majalah, koran, atau karya tulis lainnya yang relevan dengan topik, fokus atau variabel penelitian.

Definisi Operasional dan Pengukuran Variabel

Definisi operasional variabel variabel pada penelitian ini adalah :

1. Kualitas Pelayanan

Kualitas pelayanan adalah ukuran suatu pelayanan yang diberikan oleh prrodusen atau penyedia barang / jasa kepada pelanggan dalam rangka memenuhi ekspektasi / harapan pelangan.

2. Ekuitas Merek

Ekuitas merek adalah nilai suatu merek berdasarkan seberapa kuat merek tersebut mempunyai loyalitas merek, kesadaran konsumen akan nama merek, kualitas yang dipersepsikan, asosiasi merek, dan berbagai aset lainnya serta merupakan nilai tambah bagi produk itu sendiri.

3. Kepuasaan Konsumen

Kepuasan pelanggan adalah suatu ungkapan perasaan dari pelanggan apabila kinerja suatu produk / jasa sesuai dengan ekspektasi / harapan 
pelanggan atau melebihi dari harapan

/ ekspektasi pelanggan itu sendiri mengenai produk / jasa tersebut.

\section{Pengukuran Variabel}

Variabel yang merupakan variabel bebas (independent) adalah variabel kualitas pelayanan (X1), ekuitas merek (X2). Sedangkan untuk variabel terikat (dependent) adalah variabel kepuasan konsumen $(\mathrm{Y})$.

Skala pengukuran yang digunakan untuk penelitian ini adalah skala Likert. LSR (skala Likert) adalah metode pengukuran sikap (attitude) yang banyak digunakan dalam penelitian sosial karena kesederhanaannya.

Sugiyono mengemukakan bahwa untuk keperluan analisis Kuantitatif, maka jawaban itu dapat diberi skor, misalnya :

1. Setuju/selalu/ diberi skor 5

2. Setuju/sering/positif diberi skor. 4

3. Ragu-ragu/kadang-kadang diberi skor 3

4. Tidak setuju diberi skor 2 .

5. Sangat tidak setuju diberi skor 1 .

\section{Teknik Analisa Data}

Karena penelitian ini adalah penelitian bersifat kuantitatif maka data yang diperoleh dari responden lewat kuesioner dikodekan sesuai dengan skala Likert 1 - 5, dan kemudian ditabulasi dengan menggunakan analisis statistik dengan program komputer (Program SPSS 20) Windows. Data yang terkumpul akan dianalisis dengan teknik statistik regresi linier berganda dengan korelasi yaitu untuk mengetahui seberapa kuat hubungan antara variabel-variabel, baik secara sendiri-sendiri maupun parsial, sebagaimana yang tercermin pada rumusan masalah, tujuan dan hipotesis penelitian, dilengkapi pengujian hipotesis secara parsial dengan uji t dan secara simultan atau serentak dengan uji $F$, perhitungan koefisien determinasi serta koefisien Korelasi.

\section{Analisis Regresi Linier Berganda}

Analisis regresi linier berganda adalah metode statistika yang digunakan untuk membentuk model hubungan antara variabel terikat (dependen; respon; Y) dengan lebih dari satu variabel bebas (independen, prediktor, X). Analisis regresi setidak-tidaknya memiliki 3 kegunaan, yaitu untuk tujuan deskripsi dari fenomena data atau kasus yang sedang diteliti, untuk tujuan kontrol, serta untuk tujuan prediksi.

Persamaan regresi untuk dua prediktor adalah :

$Y=a+b_{1} X_{1}+b_{2} X_{2}$ 
Persamaan regresi untuk tiga prediktor adalah :

$Y=a+b_{1} X_{1}+b_{2} X_{2}+b_{3} X_{3}$

Persamaan regresi untuk $\mathrm{n}$ prediktor adalah:

$Y=a+b_{1} X_{1}+b_{2} X_{2}+\ldots \ldots \ldots+b_{n} X_{n}$

\section{HASIL PENELITIAN DAN}

\section{PEMBAHASAN}

HASIL ANALISA DATA

\section{Analisis Regresi Linier Berganda}

Berdasarkan hasil perhitungan dan pengolahan data dengan menggunakan bantuan program SPSS Version 20.0, maka ringkasan hasil pengolahan data dengan menggunakan SPSS dapat dilihat dalam Tabel

Ringkasan Hasil Perhitungan dan Pengolahan Data Dengan Program SPSS Version 20.0

$$
\begin{aligned}
& Y=b_{0}+b_{1} X_{1}+b_{2} X_{2}+\varepsilon \\
& Y=4,861+0,792 X_{1}-\mathbf{0 , 3 1 1} X_{2} \\
& \text { Konstanta } X_{0} \text { sebesar } 4,861
\end{aligned}
$$

memberikan pengertian bahwa jika kualitas pelayanan dan ekuitas merek konstan atau sama dengan nol (0), maka besarnya kepuasan konsumen adalah sebesar 4,861 satuan.

$$
\text { Selanjutnya nilai } X_{1} \text { yang }
$$
merupakan koefisien regresi dari variabel $\mathrm{X}_{1}$ (Kualitas Pelayanan) sebesar 0,798 mempunyai arti bahwa jika terjadi perubahan kualitas pelayanan sebesar 1 satuan, maka kepuasan konsumen akan mengalami kenaikan atau peningkatan sebesar 0,798 satuan dengan asumsi variabel lainnya tetap atau konstan.

$$
\text { Kemudian nilai } \mathrm{X}_{2} \text { merupakan }
$$
koefisien dari variabel $\mathrm{X}_{2}$ sebesar $-0,311$. Artinya jika tidak diperhatikan oleh produsen, maka ekuitas merek akan berkurang sebesar 0,311.

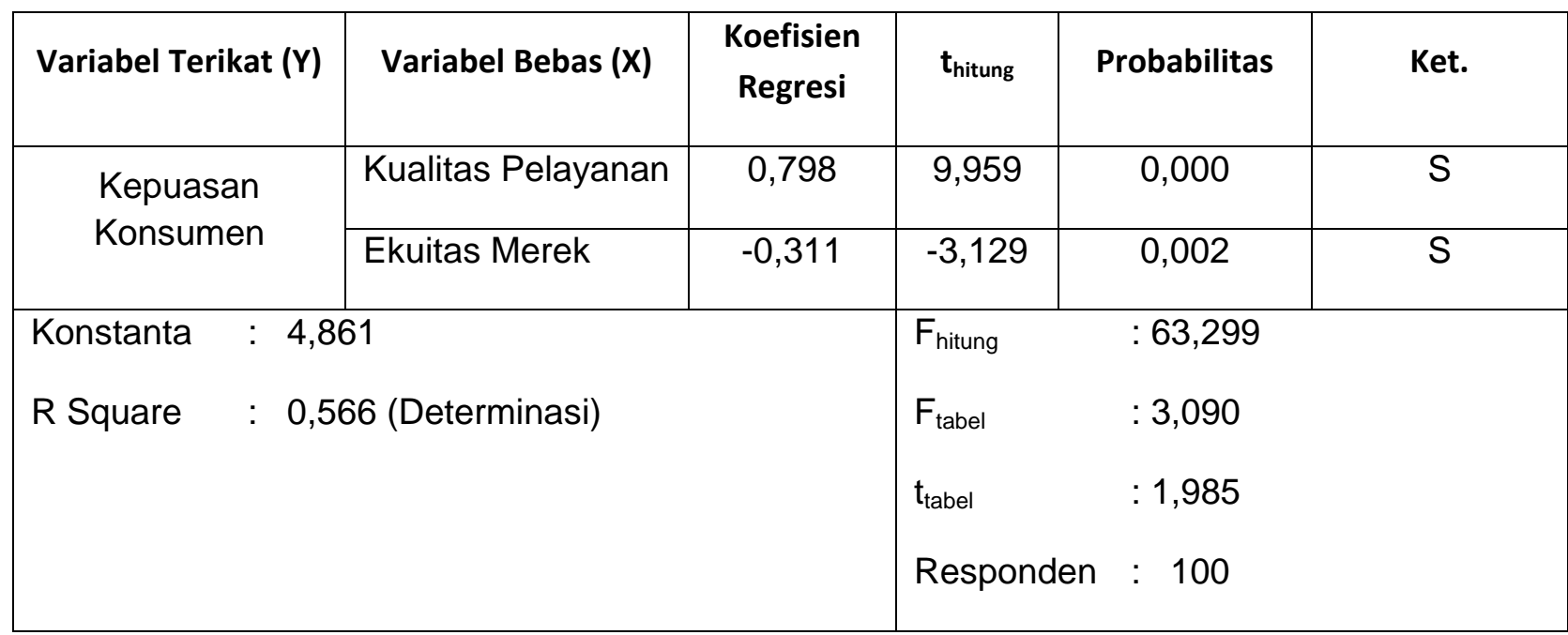


Pengujian Hipotesis

1. Uji Simultan (F)

Tabel ANOVA variabel-1) $=2$, dan df $2(n-k-1)$ atau $(100-2-$

1) $=97$ dimana $\mathrm{n}$ adalah jumlah data dan $\mathrm{k}$ adalah jumlah variabel. Hasil yang diperoleh adalah 3,090. Jadi nampak bahwa $F_{\text {hitung }}>$

\begin{tabular}{|rl|r|r|r|r|r|}
\hline \multicolumn{1}{|l|}{ Model } & Sum of Squares & \multicolumn{1}{|c|}{ Df } & Mean Square & \multicolumn{1}{c|}{ F } & \multicolumn{1}{c|}{ Sig. } \\
\hline \multirow{4}{*}{1} & Regression & 403.124 & 2 & 201.562 & 63.299 & $.000^{\mathrm{b}}$ \\
& Residual & 308.876 & 97 & 3.184 & & \\
& Total & 712.000 & 99 & & & \\
\hline
\end{tabular}

a. Dependent Variable: Kepuasan Konsumen

b. Predictors: (Constant), Ekuitas Merek, Kualitas Pelayanan

$\mathrm{F}_{\text {tabel }}$ maka berarti $\mathrm{H}_{\mathrm{a}}$ diterima. Berdasarkan

Anova atau abalisis varian merupakan uji koefisien regresi secara bersama sama (uji F) untuk menguji signifikansi pengaruh beberapa variabel independen terhadap variabel dependen. Hipotesis yang berlaku pada uji F ini adalah :

- Ho : Kualitas pelayanan dan ekuitas merek secara bersama - sama tidak berpengaruh terhadap kepuasan konsumen

- Ha : Kualitas pelayanan dan ekuitas merek secara bersama - sama berpengaruh terhadap kepuasan konsumen

Kriteria Pengujian :

- Jika $\mathrm{F}$ hitung $<\mathrm{F}$ tabel, maka Ho diterima

- Jika F hitung > F tabel, maka Ho ditolak

Uji F ini menggunakan bantuan program SPSS Version 20.0 maka dapat diketahui hasil $F_{\text {hitung }}=63,299$. $F_{\text {tabel, }}$ pada tingkat signifikansi 0,05 dengan df 1 adalah (jumlah tingkat signifikansi, dimana dari Tabel 4.5 diketahui tingkat signifikansi adalah 0,000. Oleh karena probabilitas 0,000 lebih kecil dari 0,05 , maka berarti $\mathrm{H}_{\mathrm{a}}$ diterima.

Hasil uji F menyatakan bahwa $\mathrm{H}_{a}$ diterima, artinya kualitas pelayanan dan ekuitas merek berpengaruh secara signifikan terhadap kepuasan konsumen pengguna blackberry curve 9300 .

\section{Uji Parsial (T)}

Uji hipotesis secara parsial dimaksudkan untuk mengetahui pengaruh masing-masing $\mathrm{X} 1$ (kualitas pelayanan) dan X2 (ekuitas merek), terhadap $\mathrm{Y}$ (Kepuasan konsumen).

Berdasarkan hasil perhitungan yang dapat dilihat pada tabel diperoleh hasil $t_{\text {hitung }}$ masing masing variabel. Nilai ini digunakan 
untuk mengukur tingkat signifikansi pengaruh $\mathrm{X} 1$ terhadap $\mathrm{Y}$ dan $\mathrm{X} 2$ terhadap Y. Derajat kebebasan $\mathrm{df}=$ $\mathrm{n}-\mathrm{k}-1$ dimana $\mathrm{n}$ adalah jumlah sampel/data dan $\mathrm{k}$ adalah jumlah variabel independen, sehingga $\mathrm{df}=$ $100-2-1=97$ pada signifikansi $0,05 / 2=0,025$. Hasil yang diperoleh untuk $t_{\text {tabel }}$ adalah 1,985.

Kriteria pengujian hipotesis :

- Jika $t_{\text {hitung }}<t_{\text {tabel }}$ atau signifikansi $>0,05$ maka Ho diterima

- Jika $t_{\text {hitung }}>t_{\text {tabel }}$ atau signifikansi $<0,05$ maka Ho ditolak.

Setelah diperoleh hasil $t_{\text {tabel }}$ diatas dan berdasarkan pada hasil output SPSS mengenai uji parsial maka :

1. Hasil thitung untuk variabel $\mathrm{X}_{1}$ (Kualitas Pelayanan) $=9,959$ dan $t_{\text {tabel }}=1,985$. Karena $t_{\text {hitung }}>$ $t_{\text {tabel }}$ maka $\mathrm{H}_{\mathrm{a}}$ diterima. Atau dapat juga dilihat signifikan $\mathrm{t}$ sebesar 0,000, lebih kecil dari 0,05 ini menunjukkan bahwa $\mathrm{H}_{\mathrm{a}}$ diterima. Artinya variabel kualitas pelayanan berpengaruh secara signifikan terhadap kepuasan konsumen pengguna blackberry curve 9300 .

2. Hasil thitung untuk variabel $\mathrm{X}_{2}$ (ekuitas Merek) $=-3,129$ dan $t_{\text {tabel }}=1,985$. Karena $t_{\text {hitung }}<t_{\text {tabel }}$ maka $\mathrm{H}_{0}$ diterima. dengan signifikan $t$ sebesar 0,002 . Artinya ekuitas merek tidak berpengaruh tetapi signifikan kepuasan konsumen pengguna blackberry curve 9300 .

\section{Pembahasan}

\section{Pengaruh Kualitas Pelayanan Terhadap Kepuasan Konsumen}

Berdasarkan hasil pengujian hipotesis secara parsial yang dapat dilihat pada Tabel diperoleh hasil sebagai berikut: Variabel $\mathrm{X}_{1}$ (Kualitas Pelayanan) memiliki koefisien regresi sebesar 0,798, $t_{\text {hitung }}$ sebesar 9,959, $t_{\text {tabel }}$ sebesar 1,985 dan nilai signifikansi sebesar 0,000. Artinya jika kualitas pelayanan naik 1 satuan maka kepuasan konsumen naik 0,798 . Jadi produsen harus mengoptimalkan kualitas pelayanan demi meningkatkan kepuasan konsumen. Karena $t_{\text {hitung }}>t_{\text {tabel }}$ dan nilai signifikansi dibawah 0,05 maka variabel $X_{1}$ (Kualitas Pelayanan) berpengaruh secara signifikan terhadap variabel Y (Kepuasan Konsumen).

Jadi hasil dari penelitian ini menyatakan bahwa kualitas pelayanan berpengaruh signifikan terhadap kepuasan konsumen.

sebesar $-3,129, t_{\text {tabel }}$ sebesar 1,985 dan nilai signifikansi sebesar 0,002 . Jadi karena $t_{\text {hitung }}$ 
$<t_{\text {tabel }}$ dan nilai signifikansi dibawah 0,05 maka variabel $\mathrm{X}_{1}$ (Ekuitas Merek) tidak berpengaruh terhadap variabel $Y$ (Kepuasan Konsumen). Jika produsen Blacberry tidak memperhatikan mengenai ekuitas merek maka akan terjadi penurunan sebesar 0,311 . Oleh sebab itu produsen harus meningkatkan ekuitas merek agar konsumen lebih puas menggunakan Blackberry. Hasil dari penelitian ini menunjukkan bahwa ekuitas merek tidak berpengaruh terhadap kepuasan konsumen.

\section{Pengaruh Kualitas Pelayanan dan}

\section{Ekuitas Merek Terhadap Kepuasan}

\section{Konsumen Secara Simultan}

Berdasarkan hasil pengujian hipotesis secara simultan yang dapat diliihat pada tabel, maka diperoleh $F_{\text {hitung }}=63,299, F_{\text {tabel }}$ $=3,090$, dan tingkat signifikansi adalah 0,000. Karena $F_{\text {hitung }}>F_{\text {tabel }}$ dan tingkat signifikansinya di bawah 0,05 maka, kualitas pelayanan dan ekuitas merek berpengaruh secara bersama - sama terhadap kepuasan konsumen.

\section{PENUTUP}

\section{KESIMPULAN}

Berdasarkan hasil penelitian yang telah dilakukan, maka dapat ditarik kesimpulan sebagai berikut:
1. Variabel kualitas pelayanan berpengaruh signifikan terhadap kepuasan konsumen karena nilai $t_{\text {hitung }}$ sebesar 9,959 lebih besar dari pada nilai $t_{\text {tabel }}$ sebesar 1,985 dengan tingkat signifikan 0,000 yang lebih kecil dari 0,05, maka hipotesis ditolak.

2. Variabel ekuitas merek tidak berpengaruh terhadap kepuasan konsumen karena nilai $t_{\text {hitung }}$ sebesar 3,129 lebih kecil dari pada nilai $t_{\text {tabel }}$ sebesar 1,985 dengan tingkat signifikan 0,002 yang lebih kecil dari 0,05, maka hipotesis diterima.

3. Variabel kualitas pelayanan dan ekuitas merek secara bersama - sama berpengaruh terhadap kepuasan konsumen karena $F_{\text {hitung }}$ sebesar 63,299 lebih besar dari $F_{\text {tabel }}$ sebesar 3,090 dengan dan tingkat signifikansi adalah 0,000 maka hipotesis ditolak.

\section{SARAN}

Bagi pihak RIM sebagai produsen ponsel Blackberry harus lebih lagi meningkatkan kualitas pelayanan yang lebih baik lagi kepada konsumen sehingga konsumen tidak berpindah atau beralih kepada pihak lainnya. Meningkatkan kualitas pelayanan merupakan strategi yang penting dalam mendapatkan konsumen baru maupun mempertahankan 
konsumen yang telah ada. Produsen lebih mengoptimalkan kualitas pelayanan agar kepuasan pelanggan semakin tinggi. Pihak RIM juga harus memperhatikan ekuitas merek. Jika pihak RIM tidak memperhatikan ekuitas merek maka akan terjadi penurunan terhadap tingkat kepuasan konsumen yang berdampak pada menurunnya tingkat penjualan produk. Pihak RIM harus lebih gencar lagi meningkatkan ekuitas merek dari blackberry tersebut agar semakin banyak konsumen yang menggunakan blackberry maka semakin besar juga keuntungan yang diperoleh.

\section{DAFTAR PUSTAKA}

Bambang, 2012. Smartphone Android menguasai Pangsa Pasar Selama Kuartal Pertama 2012.

http://gadgetan.com/2012/05/smartphonedengan-osandroid-menguasai-pangsa-pasarselama-kuartal-pertama-2012/. Diakses Juli, 05, 2012

Badan Pusat Statistik Kota Manado. Penduduk Per Kecamatan.http://

manadokota.bps.go.id/narasi.php?data=pen duduk\&kat=1 Diakses Juli, 06, 2012

Dowi, Mas, 2011. Android Kuasai Penjualan Smartphone Di 6 Negara.

http://zonaaneh.blogspot.com/2011/07/andr oid-kuasai-penjualan-s 2012. martphone-di.html. Diakses Juli, 05,

Karimuddin, Amir. 2012. RIM Harapkan Pengguna BlackBerry di Indonesia Capai 9.7 Jutahttp://dailysocial.net/2012/01/05/rimharapkan-pengguna-
Blackberry-di--indonesia-capai-9-7juta-tahun-2015/Tahun 2015.

Diakses Juli, 05, 2012.

Kotler, Philip. 2001. Manajemen Pemasaran di Indonesia : Analisis,

Perencanaan, Implementasi dan Pengendalian. Salemba Empat. Jakarta.

Kotler, Philip. 2002. Manajemen Pemasaran di Indonesia : Analisis, Perencanaan Implementasi dan Pengendalian. Salemba Empat. Jakarta.

Kotler, Philip and Gary

Amstrong,2007.Dasar - Dasar Pemasaran Jilid 1.Edisi

Kesembilan.Indeks.Jakarta

Kotler, Philip and Kevin L.

Keller,2009.Manajemen Pemasaran Jilid 1.Edisi

Keduabelas.Indeks.Jakarta.

Priyatno, Duwi, 2009. 5 Jam Belajar Olah Data dengan SPSS 17. Penerbit Andi. Yogyakarta.

Purwanti, Tenni. 2012. Indonesia, Pasar Menggiurkan Bagi Blackberry. http://tekno.

kompas.com/read/2012/02/22/10251619/Ind onesia.Pasar Bandung.

Sulaiman, Mochamad, Metode Penelitian. http://blog.elearning.unesa.ac.id/ mochamad -sulaiman/metodepenelitian. Diakses Juli, 05, 2012.

Sumarwan, Ujang, Ahmad Jauzi, Asep Mulyana, dkk, 2011. Riset Pemasaran dan Konsumen : Panduan Riset dan Kajian : Kepuasan, Perilaku Pembelian, Gaya Hidup, Loyalitas dan Persepsi Risiko. Seri: 1. IPB Press. Bogor.

Swastha, Basu. 2000. Azas-azas Marketing. Liberty. Yogyakarta.

Tjiptono, Fandy. 2000. Prinsip \& Dinamika Pemasaran. Edisi Pertama. J \& J Learning. Yogyakarta.

Tjiptono, Fandy. 2001. Strategi Pemasaran. Edisi Pertama. Andi Ofset.Yogyakarta.

Tjptono. 2007. Strategi Pemasaran. Edisi Pertama. Andi Ofset. Yogyakarta. 

